\title{
The Grammar of Poetry
}

Don't tell your friends about your indigestion:

"How are you!" is a greeting, not a question.

-Arthur Guiterman, $A$ Poet's Proverbs

In the previous chapter we saw that noun-epithet formulas, uttered within the specific context of their staging formula, constitute an important speech ritual, with a meaning that exceeds the propositional content of a phrase "x saw/answered y." The speech ritual is a matter of special speech in that it pertains specifically to the performance as the reenactment of the heroic events from the past. Important aspects of noun-epithet formulas, however, are left unaccounted for in this discussion. These can be summed up by the observation that the noun-epithet formula is not only uttered within a context; it also constitutes a context, a metrical one that is defined with respect to the metrical period and its recurrence in the Homeric performance. In the present chapter I offer a metrical discussion of the noun-epithet formula, which complements the semantic and thematic one of the previous chapter.

The relation between phrases and meter takes us back to Chapter 6 . There I argued that meter as a rhetorical strategy may emphasize or otherwise manipulate the typical segmentation of the spoken medium. The rhythmical, prosodic features of intonation units may become regularized to the point that they become metrical. So meter emerges from discourse, as I argued, but at some point it becomes so rigid as to constitute a structure in itself, regulating the flow of speech. The shift from meter as nascent and emergent to meter as a structure in its own right implies a parallel shift in perspective on the Homeric epithet. In the previous chapter, where staged epiphany was at the center of the discussion, the focus was not even on the 
epithet as such and its meaning, but on the noun-epithet formula as a whole, of which the epithet is an integral part. In the present chapter we will be viewing epithets as separate elements that can be added to a name or omitted. This different conception and use of epithets is occasioned, I argue, by the development of meter from regularized speech rhythm to poetic, structuring principle.

As in the previous chapters I start from the intonation unit of speech. Viewing noun-epithet formulas as stylized intonation units, we note that metrical expansion may apply both to the internal structure of units as they are defined with respect to the metrical period and to the way in which they relate to each other. Conditioned by the contexts of meter, an epithet may expand a noun or name, and the combination of the epithet with the name as one unit may expand the idea expressed by another unit-a phenomenon I discussed in Chapter 5 as "addition" and "framing." Within the context of meter I shall speak of expanding phraseology as material that is peripheral with respect to a given nucleus. On the level of the single intonation unit or formula a nucleus can be equated with the "essential idea" of Parry's definition of the formula; ${ }^{1}$ but it may also be the framing unit that serves as starting point for the unit(s) to follow, this time defined not only as cognitive but also as metrical moments.

Peripheral elements constitute the formulaic element in Homeric metrical diction, in the strong sense of the formulaic system proposed by Parry and Lord. ${ }^{2}$ We only have to look at the epithets for, say, Odysseus to see that they are all of a different length, and so economical in Parry's sense. But the metrically conditioned deployment of peripheries is merely the area where the stylization of speech comes to be defined in terms of meter rather than vice versa, without its constituting Homeric discourse as such. Formulaic peripheries are the tip of an iceberg, and as such they are not merely inevitable stopgaps or traditional formulas that serve the purpose of versification. Peripheral elements are the most extreme, grammatical case of the expansion phenomena I discussed in Chapter 5 . Just as a framing unit may be uttered not for its own sake but to accommodate the description that is to follow, so it is the periphery, not the nucleus, that constitutes the really essential idea-it verbalizes the detail that is the concern of epic

1 Parry I97I: I 3, 272. See also Chapter I above, as well as the discussion of Parry's definition in Bakker 1988: I 52-64.

2 See Chapter I above, as well as Bakker I995. 
discourse. To put this aesthetic of expansion in perspective, let us now turn for the last time to the phenomenon of recurrence in ordinary speech.

\section{Routinization and Deroutinization}

The presence of formulas in a language or idiom is obviously a factor conducive to repetition in the discourses conducted in that language. In line with the argument of Chapter 7, however, in which I suggested that linguistic expressions be viewed as behaviors rather than as things, we may also reverse the statement: formulas are not only a source for repetition, but also a consequence of certain recurrent contexts in which a given expression is required. The result of such recurrence may be routinization: within one's total behavior a given way of expression may prove so useful as a method of coping with a recurrent speech situation that it becomes standardized, serving as the model for future expressions to be uttered under the same circumstances. The routinization may even increase to the point at which the expression comes to be used in situations that are merely similar, not identical, to the original context. In such cases the original meaning of the phrase may come to be bleached, by the loss of one or more features proper to the original context. ${ }^{3}$

We saw in Chapter 6 that what is involuntary has a natural counterpart in deliberate enhancement: the segmentation of speech that is due to cognitive constraints was shown to be stylized by rhythm. In the same way the routine or idiomatic utterance of given expressions in ordinary speech is balanced by an opposite phenomenon: the tendency to use routinized, idiomatic phrases for new purposes. In terms that have been used in the study of grammar, one might speak of a process of deroutinization as a counterpart of routinization. ${ }^{4}$ This tendency to deroutinize certain ways of expression may be called innovation, not in the sense that original and

3 This is what I have discussed elsewhere (Bakker I988: I4-I8, 239-65, 273-74) as the use of a linguistic item outside its "prototypical" use in the original context. The principle of prototypicality derives from the study of how people create and experience categories (Rosch 1973; I978) and has been applied to the study of linguistic categories such as noun or verb (e.g., Hopper and Thompson 1984; Givón I984-9 I: I 2-23) as well as of the lexicon (e.g., Geeraerts I988). The idea of routinization, furthermore, can be applied not just to the utterance of phrases but also to the system of the language itself, grammar being the process by which certain phrases become grammatical by constant recurrence. On this process of grammaticalization, see Heine et al. I99 I; Hopper and Traugott 1993; cf. Bakker 1995: 106-8.

${ }_{4}$ See Hopper and Traugott 1993: 65. 
unique expressions are produced for which no model exists yet, but that new things are done with old means. In this sense, the deroutinization of expressions and constructions in order not to have to make new phrases is a matter of simplicity or "economy," a term to which Parry's technical usage lends a special significance.

As far as recurrence in speech is concerned, then, we may distinguish three categories or stages: (I) a formative stage, in which a given expression comes to serve a function in certain contexts; (2) a routinization stage, in which the expression, now an idiom, is uttered under circumstances that are in part different from those for which it was originally devised; and (3) a deroutinization stage, in which the expression comes to serve a new function. These three categories will serve as a general framework for a discussion of noun-epithet formulas, to which we now turn.

\section{The Grammar of Poetry}

It is clear that meter will have a large role to play when we try to study the recurrence of Homeric expressions along the lines just sketched. The question is exactly what role. The influence of meter was formulated by Parry, as we saw in Chapter I, in terms of formulaic systematicity, extension, and economy. Following this lead, Lord described the influence of meter as a grammar of poetry: "In studying the patterns and systems of oral narrative verse we are in reality observing the 'grammar' of the poetry, a grammar superimposed, as it were, on the grammar of the language concerned. Or, to alter the image, we find a special grammar within the grammar of the language, necessitated by the versification." 5

It is true enough that the verse necessitates certain patterns and regularities, but it is equally true, as I argued above, ${ }^{6}$ that meter is not an external constraint, independent of discourse. In fact, meter is conditioned by certain phrases just as much as it is itself a conditioning factor, and we might see its relation to the stylized speech units of epic discourse as reciprocally defining: phrases confer their rhythmical and prosodic properties on meter, after which they become metrical, part of the system that is meter and occurring within the contexts created by that system. Nounepithet formulas are a particularly clear example of this phenomenon, as is

${ }^{5}$ Lord 1960: $35-36$.

${ }^{6}$ See Chapters 6 and 7. 
pointed out by Kevin O'Nolan in an article on this feature of heroic narrative: ${ }^{7}$

Much of the examination of formulas in Homer seems to assume a fixed dactylic hexameter into which the poet-composer must fit his various formulas like so many building bricks. The fact seems to be that epithet formulas are a feature of heroic storytelling, not simply of epic hexameter. It must be obvious that these formulas of their nature have a slow organic growth and to assume that this slow growth took place in the context of an established hexameter verse is unreasonable. ... The hexameter cannot have sprung fully fledged into existence but is likely to have developed . . . from a prototype which had a fixed tail-end and a free fore-part. One might imagine a sort of creeping paralysis of versification starting at the line end. The preponderance of epithet nouns at that point suggests that that feature of heroic storytelling helped to develop and mould the hexameter.

The exact reconstruction of the origin of the hexameter cannot be our concern here. What is of interest is that the hexameter, as the rhetorical strategy discussed in Chapter 6, was not always there, and that the thematically important noun-epithet phrases have, diachronically, contributed more than other phrases to the emergence of meter. Achilles, Odysseus, and the other major figures of epic have helped, via their names, to shape the epic verse, a medium that came to constitute the universe within which their kleos is reenacted.

Thus whereas all phraseology is subject to meter such as we observe it in our Homeric text, some phrases are more metrical in essence than others. The importance of this statement lies in the double nature of the word "metrical," referring both to what contributes most to meter and to what behaves most systematically and economically within the metrical grammar of poetry. The central concern of the present argument is that it is the same phrases to which both senses of "metrical" apply. This observation may lead us back to the three stages mentioned in the previous section, which we may now reformulate in terms of meter: (I) a given phrase may serve an important and recurrent function in the discourse of special speech, so that (2) its rhythm becomes so regularized as to become meter,

7 O'Nolan I969: I4, I7. Cf. Nagy 1974: I40-49; I992b: I8-35, esp. 29-32; on the great antiquity of noun-epithet formulas (going back to Mycenaean or even proto-Mycenaean times), see most recently Ruijgh I995: 75-9I. 
after which (3) it may come to serve new functions within the very metrical contexts that it has thus created. Applied to the specific case of nounepithet formulas, this tripartite scheme yields the following picture:

I. Formative Stage. In effecting a n epiphany that marks founding action crucial for the reality of the performance (see Chapter 7), the noun-epithet formula, along with its staging formula, serves a commonly needed discourse function.

2. Routinization Stage. The use of the noun-epithet formula is triggered by the preceding staging formula, which is no longer motivated by the momentous circumstances of the previous stage; in other words, the noun-epithet formula along with its staging formula has become an idiom, and the bond between the two has become fixed.

3. Metrical Stage. The noun-epithet formula occurs in isolation from a staging formula; the noun-epithet formula comes to be reanalyzed as a metrical phrase, so that it can serve a function in the expansion aesthetic of Homeric discourse, while its original meaning is still visible; on account of this original meaning the formula can function, according to the rules of the grammar of poetry, as a periphery with respect to a nucleus, or the epithet as periphery with respect to the noun.

Before we continue with the discussion and illustration of these three possibilities, it is worth emphasizing that although the idea of stage implies the notion of consecutive development, the relationship between a nounepithet formula of the first stage and one of the third stage is not simply a diachronic one in the sense that the one precedes the other in time: nounepithet formulas continue to be used in formative, epiphanic contexts, even after the metrical stage has been reached. As in ordinary speech, old and young in Homeric diction exist side by side, and two uses of a given expression between which a diachronic relation can be established are often, synchronically, simply different senses or uses of the expression. The decision, then, not to treat contexts in which staged epiphanies occur as older than the other contexts does not so much bespeak a Unitarian stance with regard to the Homeric Question as an insight drawn from the study of speech. ${ }^{8}$

8 On synchrony and diachrony in the study of linguistic items see the discussion of the particle $\pi \varepsilon \rho$ in Bakker 1988: 73-75, I20, I46 n. 38-39; 1993d: I 5. The synchronic productivity of what must belong to a diachronically older stage is particularly pertinent in Homer, of course, because 
The development from stage to stage does not simply involve an increase in the role of meter. Meaning is also crucially involved, in that the metrical behavior of the noun-epithet formulas as optional third-stage peripheries would be impossible without their essential original meaning in the first stage. Illustration of this principle will be my prime concern at the end of this chapter. The first of these stages has already been discussed in the previous chapter. So I continue now with the second one.

\section{Beyond Staging: Routinization}

It is easy to observe that noun-epithet formulas and their staging formulas, apart from the specific contexts in which they effect a staged epiphany as described in the previous chapter, are examples of idiomatic rigidity. ${ }^{9}$ First we note that after a staging formula (e.g., tòn d' apameibómenos proséphē 'and him answering he addressed'), the occurrence of a noun-epithet phrase is so routinized, indeed obligatory, as to be virtually a matter of a grammatical rule. ${ }^{10}$ It follows that instead of competing with other kinds of expression within the context created by a staging formula, the noun-epithet formulas compete with each other, and this substitutability within a limited set of phrases is connected with their rhythmical and prosodic equivalence: they contract paradigmatic, systematic relationships with each other on the basis of their rhythmical profiles. This circumstance, we note, is nothing other than Parry's principle of extension and economy of formulaic systems, and we are now in a position to see that this regularity is not only a source but also a consequence of epic verse-making. ${ }^{11}$

of the coexistence of different dialects, representing different stages in the development of epic diction; see Ruijgh I995: 59-9I.

9 See Kiparsky's account of Homeric formulas in general (1970́: 73-84) in terms of the "bound phrases" of ordinary language. See also Chapter 7 above.

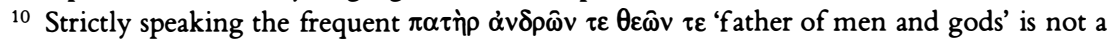
noun-epithet formula, but for the purposes of Chapter 7 it can count as one. In some cases, we see a noun followed by an independent clause (Od. I 5.434), a relative clause (Od. I 5.430), or a

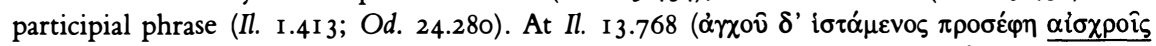

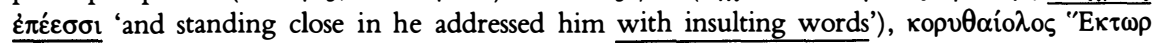
'Hektor with the flickering helmet' has apparently been judged less pertinent than the speech description; see also Edwards I970: I0-I2. Cf. also Il. 3.396, where a modified perception

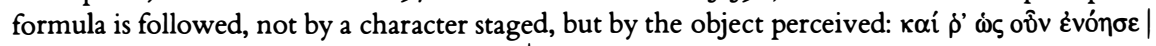

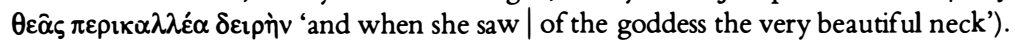

${ }^{11}$ For more detail on this point, see Bakker I995; for extension and economy, see also Chapter I above. 
Furthermore, staging formulas of any length and type always precede noun-epithet phrases, an ordering that is obviously in the nature of the very concept of staging. ${ }^{12}$ This frozen syntax reveals the special role of nounepithet phrases in the semantics and metrics of the epic tradition. The fixed linear ordering of the noun-epithet phrases and their stagings reflects the rigid behavior of these phrases as ritual namings in Homeric discourse: only rarely do they precede their verb, ${ }^{13}$ and their participation in the dynamics of word order in the Homeric Greek clause is quite limited. ${ }^{14}$ For example, noun-epithet phrases do not combine with the ubiquitous connective particle dé. Noun-epithet formulas are typically framed, not framing speech units as we observed in Chapter 5 . The routinized coalescence of the noun-epithet formula with the staging formula, finally, may well have produced the dactylic hexameter itself, the particularly strong bond between the staging and the epiphany being the semantic motivation for the coalescence (see also Chapter 7).

In the formative use discussed in the previous chapter, the staging formula provides a context for the noun-epithet formula, and is in its turn motivated by the importance for the performance of the moment of the epiphany. Moreover, a staging formula presents a character who is new to the stage. The exception is the introduction of speech, which can be marked as epiphanic even when the speaking character is already on the stage. ${ }^{15}$ But in general, if an epiphany is to be felicitous, the character must really appear. Thus at the sight of Patroklos about to kill Sarpedon, Zeus makes his sudden appearance in a staging plus noun-epithet formula that lifts the action from the battlefield to the divine plane, where the important conversation between Zeus and Hera concerning the fate and death of Sarpedon is to take place:

12 Parry observes (I97I: 55) that noun-epithet phrases used at the beginning of the verse (a type not discussed here) are always the subject of a verb in the preceding line. See, e.g., Zzìs

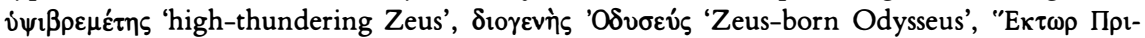
$\alpha \mu i \delta n s$ 'Hektor son of Priam'. See also Edwards I966: I 2 I-22.

13 The cases that I have found all involve (with the exception of Il. I.506) noun-epithet formulas beginning at the hephthemimeral caesura (such as $\pi \mathrm{0} \lambda$ í $\mu \eta \tau \iota \varsigma$ ' $O \delta v \sigma \sigma \varepsilon v$ ' 'many-minded

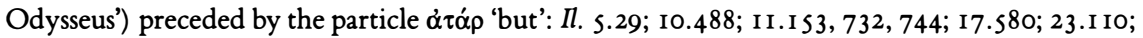
Od. 21.404; Hes. Scut. 455, 470; h. Dem. 302. These cases, however, are not so much exceptions to the rule of the order of staging and epiphany as instances of the use of epithets discussed below.

14 See also Edwards I966: I 2 I. To a limited extent noun-epithet formulas combine with the particle $\alpha \tau \alpha \dot{\alpha} \rho$; see further below.

15 An important category of the introduction of speech by a character who appears on the

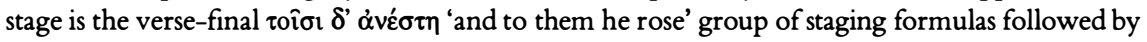
a line-long epiphany. See Chapter 7. 
$\tau 0 \grave{s} \delta \dot{\varepsilon}$ i $\delta \dot{\omega} v \underline{\varepsilon} \lambda \dot{\varepsilon} \eta \sigma \varepsilon$

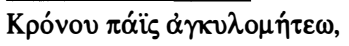

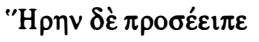

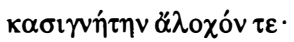

and seeing them he took pity,

the son of Kronos with the crooked

wits,

and he addressed Hera,

his sister and wife

(Il. I6.43I-32)

The staging formula, here reporting an act of commiseration, lives up to its relational potential: it stages an important new character vis-à-vis what is already on the scene, and it thus effects a shift of scene that is crucial for the reality of the epic tradition: Zeus lets himself be persuaded not to allow the anti-fact of the fated Sarpedon staying alive. ${ }^{16}$ The prevention of antiaction is also what takes place when Zeus awakes from Hera's charms, at the beginning of Book is of the Iliad. During Zeus's mental absence, the Greeks have gained the upper hand with the help of Poseidon, and the plan of Zeus and hence the course of the Iliad has nearly been reversed. The same staging formula is used to make Zeus see Hektor, but this time the circumstances under which it is used are quite different:

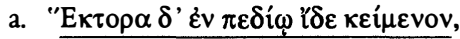

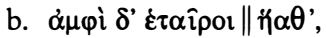

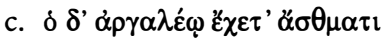
d. $\kappa \hat{p} \dot{\alpha} \pi \mathrm{t} v \dot{\sigma} \sigma \sigma \omega v$,
e. $\alpha \hat{\imath} \mu$ ' $\varepsilon \mu \varepsilon \varepsilon^{\prime} \omega v$,

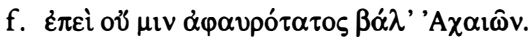

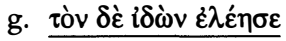
h. $\pi \alpha \tau \grave{\rho} \rho \dot{\alpha} v \delta \rho \hat{\omega} v \tau \varepsilon \theta \varepsilon \hat{\omega} v \tau \varepsilon$,

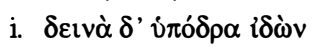

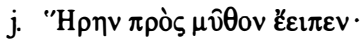

and he saw Hektor lying in the plain, and around him his comrades they sat, and he was taken by painful breathing, unconscious in his heart, vomiting blood, since not the weakest of the Achaeans had hit him, and seeing him he took pity, the father of men and gods, and looking darkly terribly, Hera he addressed.

(Il. I 5.9-I3)

At the moment of his staging in unit g, Zeus is already on the scene, and the act of perception linking him to Hektor and reported in the staging formula tòn dè idòn eléêse 'and seeing him he took pity' is already underway, as appears from unit a. Hence there is no epiphany or shift of scene, as there was in the previous case. The staging formula simply says that Zeus took

${ }^{16}$ Cf. Il. 8.350, where Hera is staged under similar circumstances. On the notion of antiaction, see Chapter 7 . 
pity, without much relational implication. ${ }^{17}$ What these differences suggest is that the staging formula, with the fixed grammatical combination of the noun-epithet phrase in its wake, has been used under circumstances that differ from the situation in which it stages an epiphany. ${ }^{18}$ In other words, the staging formula motivates the use of the noun-epithet phrase, as a routinized idiomatic reflex, but seems itself not as strongly motivated as in more prototypical situations, where the formulas have the special features I have discussed.

Thus the noun-epithet phrase occurs in what may be called a grammatical context and as part of an idiomatic expression. Yet this is not to say that it is diminished in poetic and semantic force; on the contrary, the idiomatic combination of staging and noun-epithet phrase in the excerpt from Book Is derives its significance precisely from the crucial nature of the speech action that is to follow, in which Zeus undoes Hera's scheming and firmly reestablishes the plot of the Iliad. ${ }^{19}$ In other words, the basic meaning of the noun-epithet formula persists in the idiomatic combination and motivates its use in a slightly different context. ${ }^{20}$

The case of the parallel staging formula tòn dè idòn óikt(e)ire 'and seeing him he felt compassion' is similar and may even provide evidence of a further step in the process. This commiseration formula is often considered to be synonymous with tòn dè idòn eléese, ${ }^{21}$ yet it seems to denote a more intimate relation than the latter expression: a feeling of compassion for a friend whom one sees in distress, as opposed to the emotions of Zeus, who notices that a mortal is about to die. ${ }^{22}$ As such, the formula seems to be

17 Cf. also the case of tòv $\delta \dot{\varepsilon}$ i $\delta \dot{\omega} v$ pím $\sigma \varepsilon$ 'and seeing him he shuddered', which is twice used for Diomedes reacting to Hektor menacingly approaching; once (Il. 5.596) Diomedes is new to the stage, and once (Il. I I.345) he is not.

18 In Bakker 1988: I 86-95, I have discussed this "semantic integration" of the formula.

19 In Il. I 5.54-78, Zeus actually poses as the author of the plot, summarizing the course of action and predicting the deaths of Sarpedon, Patroklos, and Hektor: words that blur the distinction between god and poet.

20 See Hopper and Traugott 1993: 90, for a discussion of this phenomenon in grammatical terms: the persistence of the original lexical meaning of an item after it has become incorporated within another word as a bound morpheme.

${ }^{21}$ E.g., Janko I992: 3 I 5, on Il. I6.5. Cf. also $\tau \grave{\omega} \delta \varepsilon \dot{\varepsilon} \pi \varepsilon \sigma o ́ v \tau$ ' $\varepsilon \lambda \varepsilon \dot{\eta} \sigma \varepsilon$ 'and when they had fallen he took pity', a staging formula that activates a character at the sight of a fallen warrior (Il. 5.56I, 610; 17.346, 352; apparently two examples of clustering).

22 The verb $\dot{\varepsilon} \lambda \dot{\varepsilon} \omega$ (and the corresponding noun $\left.\varepsilon \dot{\imath} \lambda \varepsilon_{0}\right)$ ) connotes a sense of shame, reverence, and feeling for proportion (note the frequent combination with $\alpha i \delta \omega \varsigma$ and its cognates, e.g., $I l$. $21.74 ; 22.59,82,123-24,419 ; 24.44,207,503)$ and seems therefore more apt for the expression of 
more appropriate for two characters who are already on the stage than for the activation of one character vis-à-vis another. In any case, the formula is used to convey compassionate feelings in the intimate tête-à-têtes between Patroklos and Eurupulos and between Achilles and Patroklos, as well as Achilles's sympathy for Antilokhos during the funeral games for Patroklos:

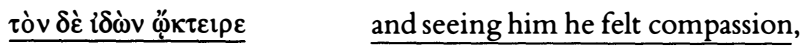

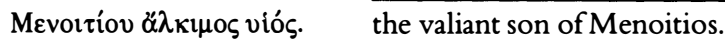

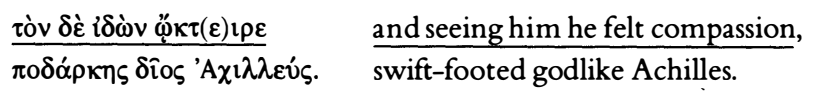

In these passages neither Patroklos nor Achilles is "staged," as the term is defined in Chapter 7; no shifts of scene are effected and no epiphanies take place. And if the interpretation of öikt(e)irōjust presented is right, then these effects are not likely to occur, since this verb would presuppose an already established relation on the scene. This would imply that on account of the meaning of its verb, the phrase tòn dè idòn óikt(e)ire is not a staging formula at all, but an expression based on one, created on the analogy of tòn dè idòn eléése. In other words, even though tòn dè idòn óikt(e)ire displays the formal characteristics of a staging formula (relational pronoun, idiomatic and fixed bond with a noun-epithet formula), it is an analogical extension of a staging formula, a phenomenon testifying to the routinization in the use of idiomatic, grammatical forms: once the use of a given form becomes so routinized as to become grammatical, it can generate new forms by analogy. Yet again, as in the case discussed earlier, the original meaning of the noun-epithet formula, for all its grammaticality, does not bleach but rather persists in the new environment: Patroklos's words addressed in compassion to Eurupulos and Achilles' address to Patroklos are among the more important speech acts in the Iliad. ${ }^{23}$

Our final example involves the phrase tòn d' hōs oûn enóêse, which we studied in the previous chapter. This formula frequently paves the way, as we saw, for a structurally important appearance on the scene. Yet this

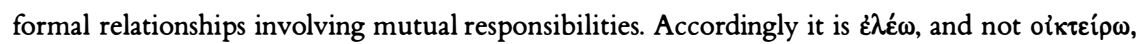
that is used in the imperative ("pity me and show respect"), at least in Homer. On $\alpha i \delta$ '́s see Redfield I994: I I 5-I 8; on $\alpha i \delta \omega ́ s$ and pity, see Cairns I993: 49, 92-93.

${ }^{23}$ On Patroklos's speech (Il. i I .8 I 6-2I) see Bakker i 997 a. 
staging device can also be used differently, in passages where staging and epiphany do not seem to be the appropriate concepts anymore. In Book $2 \mathrm{I}$ of the Iliad, as Achilles is wreaking havoc on the Trojans near the river Skamandros, he meets with Lukaon, a son of Priam whom he had previously captured and sold into slavery, but who now has returned to the battle:

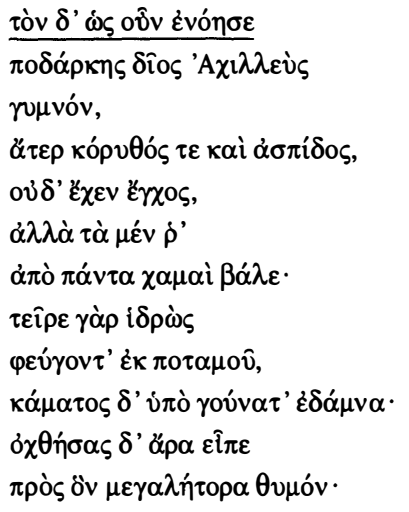

and when he saw him,

swift-footed godlike Achilles, naked,

without helmet or shield, and he did not have his spear, but all that, he had thrown it to the ground, for sweating wore him out, as he escaped from the river, and exhaustion overmastered his limbs beneath, and vexed he (=Achilles) spoke to his own great-hearted spirit.

This is not an epiphany. Achilles is already on the scene, and the staging formula does not effect a shift of scene. ${ }^{24}$ The normal perception formula, which now begins to mean simply what its words literally mean, seems to have been used in a situation other than the one for which it was originally meant. Yet this is not merely a deviant, suboptimal use of the formula, or an undesirable but inevitable consequence of oral composition. This is how language works.

\section{Reanalysis}

There are very few staging formulas without a noun-epithet phrase, but there are many noun-epithet phrases without a staging formula. To account for this asymmetrical relationship, which testifies to the metrical potential of the noun-epithet phrase in the grammar of poetry, we turn to an important concept in the study of language change: reanalysis. It fre-

${ }^{24}$ The two instances of the formula in the Odyssey (I 5.59: Telemakhos seeing Menelaos; 24.232: Odysseus seeing Laertes) are similar, in that the perceiver is already on the stage. 
quently happens that an extant form comes to be used for a new purpose, after which it can be reanalyzed in terms of the new function. A straightforward example is the development in spoken English of clauses with a verbum sentiendi (verbs expressing thought or attitude, such as I think or $I$ guess) into epistemic parenthetical phrases: ${ }^{25}$
a. I think that we're definitely moving towards being more technological.
b. I think exercise is really beneficial, to anybody.
c. It's just your point of view you know what you like to do in your spare time I think.

In example a, I think is a main clause governing a subclause introduced by the complementizer that; the complementizer is absent in example b, a phenomenon that syntacticians call that-deletion. It appears preferable, however, to analyze the case as intermediate between examples a and c; in the latter the phrase acts as an epistemic parenthetical, a phrase "functioning roughly as an epistemic adverb such as maybe with respect to the clause it is associated with." ${ }^{26}$ In other words, what is a syntactically necessary main clause in example a is reanalyzed as a syntactically optional epistemic adverb in example $c$, and the complement clause of example a is turned into a main clause modified by the adverb. ${ }^{27}$

In the case of noun-epithet formulas we are not concerned with main clauses, complement clauses, and epistemic adverbs, of course, but the general principle is similar: a necessary phrase comes to be optional, as a consequence of a shift from one function to another. The new function is owing to the recognition of meter as a grammatical factor. In the previous chapter we saw that the original context for a noun-epithet phrase is the staging formula that provides the proper environment for an epiphany. But what is staged, as we saw in Chapter 7, is not only the epic character but also his or her name: the staging formula provides an environment that not only is epiphanic but also has the potential of being reanalyzed as metrical, owing to the rhythmical profile of the noun-epithet formula. In other

25 See Thompson and Mulac I99 I: 3 I 3.

26 Ibid.

27 See also Hopper and Traugott 1993: $58-59$, on the history of the negative marker pas in French, which started out as an independent lexical item (meaning "step") that could strengthen negation in the case of verbs of movement. In this restricted context the word pas was reanalyzed as a negation marker, after which its use could be extended to verbs expressing an idea other than movement. 
words, the noun-epithet phrases may change their function from staging an entity to occupying a certain metrical space, and this shift means that they can occupy the same metrical space outside the context provided by the staging formula. Once this step has been made, the way is clear for a more general function in the grammatical system of the epic verse.

Noun-epithet formulas freely occur outside the context of speech introductions and other staging formulas. They occupy the same metrical slot, but are not tied anymore to the phrase that occupies the first half of the verse. Instead of competing with each other, they now compete with any other phrase that has the same metrical profile. ${ }^{28}$ To take a simple example, the speech unit mermêrikse d'épeita 'and then he/she pondered', which begins the metrical period, can be complemented, both semantically and metrically, by a number of expressions that elaborate on the act of deliberation, verbalized either as an adding unit or as a new step marked by the particle dé: ${ }^{29}$

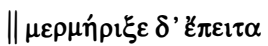

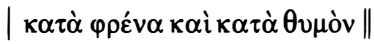

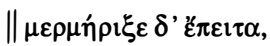

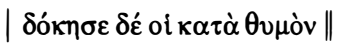

and then he pondered,

in his mind and in his spirit

(Il. 5.67I; Od. $4.117 ; 24.235)$

and then he pondered

and he decided in his spirit

Yet the second half-line could have been a noun-epithet formula which has not been used for some reason, and sometimes the noun-epithet formula actually occurs: ${ }^{30}$

28 Contrast this with Parry's remark (I97I: I4): "This fidelity to the formula is even more

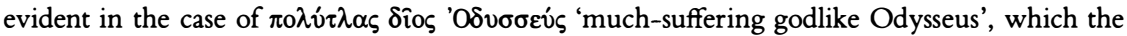
poet uses five times in the Iliad and thirty-three times in the Odyssey, without ever thinking of using other words to express the same idea, without ever so much as considering the possibility of utilizing the portion of the line taken up by the epithetic words for the expression of some original idea." It may be true that in all thirty-eight cases an alternative was never considered, but that does not mean that there are no places where the formula could have been used but has not been used. See also Bakker I 995: I I 3-18.

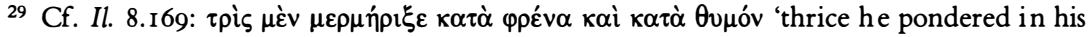
mind and in his spirit'. For a discussion of dative or prepositional expressions with words for

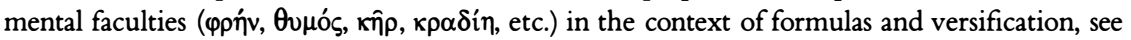
Jahn 1987.

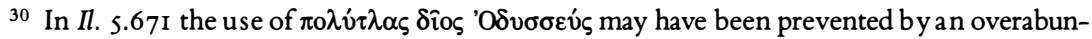
dance of the name of Odysseus in the immediate context, and in Od. 24.235 the decisive factor no doubt was the occurrence of the formula three lines earlier. 
$\| \mu \varepsilon \rho \mu \eta \dot{\rho} \rho \xi_{\varepsilon} \delta^{\prime} \varepsilon \ddot{\pi} \varepsilon \imath \imath \alpha$

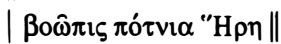

and then she pondered

cow-eyed mistress Hera

In such contexts the noun-epithet formula is optional in the sense that it is not tied up with the preceding phrase. It has been used as a phrase that fits metrically, chosen from a range of phrases with the same metrical profile. But this certainly does not mean that it is dictated by the meter. In fact, the use of boôpis pótnia Hêré 'cow-eyed lady Hera' in the example may well be necessary in the sense that any phrase can be necessary if it is the only way to say what must be said in a given context. The reason why the phrase is used is less to fill out the line with a convenient way of saying "Hera" than to serve as an introduction to the seduction scene between Hera and Zeus that follows: the pair of units quoted is balanced by a parallel pair in the next line, resulting in a rhetorical juxtaposition of Hera to Zeus, each of whom ends the metrical period in the same way:

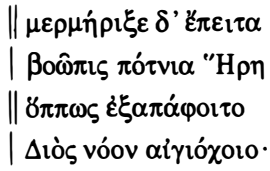

and then she pondered, cow-eyed mistress Hera, how she could deceive the mind of Aigis-bearing Zeus.

Thus it does not follow from the reanalysis of noun-epithet formulas as metrical phrases that meter becomes in and of itself a positive factor in their use. Rather, meter provides the contexts in which the use of certain phrases that lack the required metrical profile is ruled out. Only very rarely does meter constitute the sole reason for the use of a given phrase.

In certain cases the noun-epithet formula cut loose from its staging formula seems optional in the stronger sense of omissible or redundant. It can be excised, it seems, without any real loss of meaning. Yet even here meter is not the exclusive factor, with the formula as a mere stopgap. Rather, what is at stake is the stylization by means of noun-epithet formulas of the redundancy that is natural to speech. Consider for example the following cases, belonging to a type of expression that has already been at the center of attention in Chapter $s:{ }^{31}$

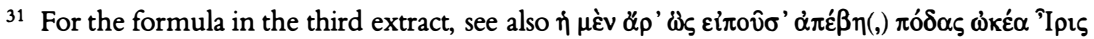
'now she, having spoken thus, went away, swift-footed Iris' (Il. 8.425; I I.2 I0; I 8.202; 24. I 88). 


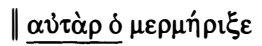

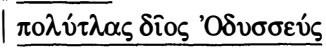

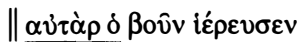

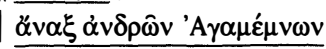

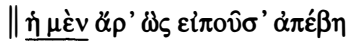

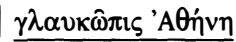

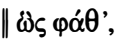

$\delta \delta \dot{\varepsilon} \kappa \lambda \iota \sigma i ́ \eta v \delta \varepsilon \kappa \iota \grave{\omega v}$

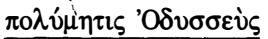

but he, he pondered

much-suffering godlike Odysseus

(Od. 5.354)

but he, he sacrificed a bull,

ruler of men Agamemnon

(Il. 2.402)

now she, having spoken thus, went away

owl-eyed Athene

(Il. 5.I 33; Od. I.3I9; 6.4I)

thus he spoke,

and he, moving to the tent

many-minded Odysseus

(Il. 10.148)

The difference with staging formulas is instructive: we saw that these expressions begin with what I called a relational pronoun in an oblique case, presenting the participant on the scene as a starting point for the appearance of the new character, the bearer of the epithet. ${ }^{32}$ What we see here, by contrast, is that the pronoun and the noun-epithet formula refer to one and the same character. The pronoun is in the nominative case, and the noun-epithet formula is added as an optional apposition. ${ }^{33}$ Instead of an epiphany, the staging of a new character vis-à-vis a character who is already on the scene, we have here the situation described in Chapter $5:$ a switch to the other character on the scene, or a return to the character who was mentioned shortly before. ${ }^{34}$ The name of this character may or may not be mentioned again, depending on whether the poet thinks that the audience will need the name to identify the character, and also on whether other material is available to fill the same metrical slot. This is not so much the encoding of founding action as the stylization of speech, where such loose additions are quite normal. And the principle regulating the stylization is the metrical grammar of the hexameter.

32 See Chapters 5 and 7.

${ }^{33}$ Cf. Il. 5.I33, quoted in the text, with Od. I5.43, in which the noun-epithet formula has been rejected in favor of a phrase that must have been felt a more useful continuation in context: $\dot{\eta}$

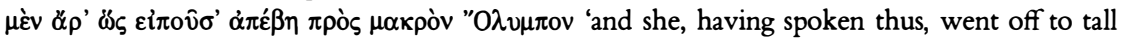
Olympos'.

${ }^{34}$ See Chapter 5. See also Bakker I995: I I I n. 35. 
But the function of noun-epithet formulas in the grammar of poetry extends further than this stylized addition of speech units. Once metrical reanalysis of the noun-epithet phrase has taken place, widening its distribution, a further reanalysis may ensue. If the noun-epithet formula has come to function as an optional, loosely added phrase, the epithet itself can also be reanalyzed as occupying a certain metrical space distinct from the name. This means that it can be left out if the metrical space which it occupies has to be used for other purposes. Consider for example the following pairs of additions to a topic switch (see also Chapter s):

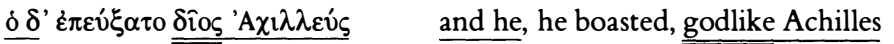

$$
\begin{aligned}
& \text { (Il. 20.388; 22.330) }
\end{aligned}
$$

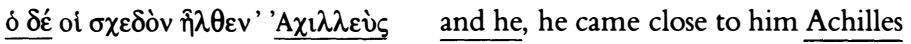

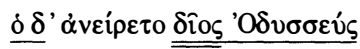

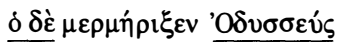

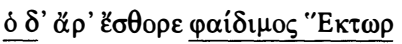

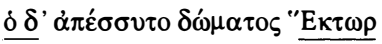

and he, he asked her, godlike Odysseus

$(\mathrm{Od} .7 .2 \mathrm{I})$

and he, he pondered, Odysseus

(Od. 6.141; 17.235)

and he, he ran forward, brilliant Hektor

(Il. 12.462)

and he, he rushed from the house, Hektor

(Il. 6.390)

We have discussed the noun-epithet phrase as an indivisible unity, the epiphany of an epic character. What we see here is a simple name that is either preceded or not preceded by an adjective. In other words, once the noun-epithet phrase has come to be used beyond its original locus, the staged epiphany, it is no longer essentially different from the simple noun, and the epithet may be dropped if need be.

\section{Nuclei and Their Peripheries}

The idea of the epithet as an optional phrase takes us into territory already covered by Parry himself, who states in his discussion of the choice of epithets: ${ }^{35}$

35 Parry I97I: 84. 
In every noun-epithet formula there are two elements, of which one is fixed and the other variable. The fixed element is the substantive. Apart from its variation in the genitive and dative plural, it has always the same metrical value, and this predetermined value is what the poet must reckon with. The variable element is the epithet. It can be assigned whatever metrical value the poet chooses, and it can begin or end pretty much as he wants. So the poet creates the noun-epithet formula of the desired measure by adding the $x$ syllables of the epithet to the predetermined syllables of the substantive.

This formulation differs from the one used here so far, in that Parry speaks of the addition of the epithet as a metrical entity, whereas I have been speaking of its omission. This difference is not arbitrary, for it depends on what we take to be the basic unit in the verse: the simple name or the combination of the name and the epithet. It is for the latter possibility that I have opted thus far, arguing for the multiple effects that staging produces, epiphanic and metrical: it is the combination of the name with the epithet, together with the staging formula, that produces the verse, and the names to which an epithet can be added at all tend to occupy, if not accompanied by the epithet, the same metrical position as they do in the fixed combination of name plus epithet, that is, in most cases, the end of the metrical period. Epithets, then, so long as we take into account their original epiphanic use, are omitted rather than added.

Parry's conception of epithets as thematically congenial additions to a name does apply, however, if we see the optional addition not as the essence of the epithet-which lies in the epiphany-but as a further stage of reanalysis, in which the epithet as a metrical form does not so much leave space for material that is more appropriate in a given context as occupy space for want of that material. In this way the epithet becomes what I have called elsewhere an element that is peripheral to a nucleus. ${ }^{36} \mathrm{~A}$ peripheral element specifies, in semantic terms, a property of the nucleus that is inherent, indeed so essential as to be self-evident. On account of this very importance, a peripheral element is optional semantically, for what is inherent in something can be expressed or it can be left understood. And this optional status in terms of meaning can be exploited for the sake of metrics and versification: one may lengthen a nucleus with the extra syllables of the periphery, but one could also leave the periphery out, without any signifi-

36 Bakker and Fabbricotti I991; Bakker 1990a; Bakker and Van den Houten 1992: 3-5. See also Bakker I988: I 86 (still without this particular terminology). 
cant loss or disruption of meaning. Thus there is no harm in calling Odysseus polúmetis 'many-minded' once one has decided to make this epithet omissible. ${ }^{37}$

In fact, there is considerable gain in doing so. The metrical reanalysis of epithets does not reduce them to what Parry calls "stylistic superfluity" that is added to an "essential idea." 38 The metrical reanalysis goes hand in hand with a semantic one, whereby the addition of the epithet becomes an aesthetic principle in its own right, a matter of ornamental extension. Viewed in this way, the grammar of epithets and other peripheral elements becomes the tip of an iceberg, the grammatical and metrical consequence of a pervasive tendency in Homeric discourse that has been discussed in various ways and from various viewpoints in Part 2 above. After defining speech as process through time in Chapter 3, I argued in Chapter 4 that time, of which there is only a limited quantity, can be an important means in a performer's hands to emphasize the importance of a given idea: what stays longer in focus is more prominent for that reason. ${ }^{39}$ In Chapter 5 I elaborated on this point by discussing the way in which a given idea can frame what lies ahead and thus organize the flow of speech. In the present context, finally, we speak of the expansion of nuclear ideas as an operation within the metrical space of the hexameter. ${ }^{40}$ Seen in terms of this metrical expansion aesthetic, the peripheral status of epithets with regard to their nouns is but a part of a much wider phenomenon.

The principal domain of operation for the peripheral expansion of nu-

37 Notice that the two central heroes, Achilles and Odysseus, the quintessential performers of founding action, and hence most amenable to staging, are also the ones whose epithets lend themselves best to reanalysis. Thus not only are the simple names (very strongly localized at the heroic end of the verse, see Kahane I994: I 56) analyzable as the omission of their epithets, but the

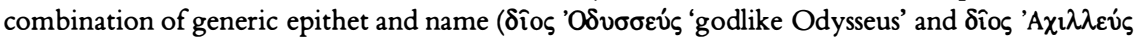
'godlike Achilles') can also be seen as involving the omission of $\pi 0 \lambda \dot{\tau} \tau \lambda \alpha \varsigma$ 'much-suffering' and

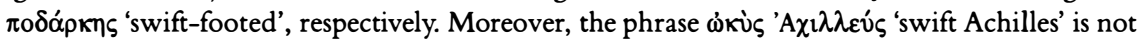

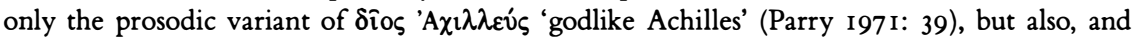
perhaps more significantly, involves the omission of $\pi$ ó $\delta \alpha \varsigma$ 'of foot'. These heroes, then, are more than any other characters, hexametrical heroes.

38 Parry I97I: I3-I4.

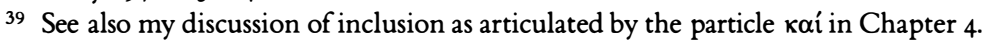

40 In his discussion of "Item Plus," Russo mentions the noun-epithet formula (I994: 378) as "one of several 'tropes of extension,' . . . the epithet bestowing an extension that is always appositional and is explanatory to the extent that it enlarges the idea or image." Russo calls the expansion aesthetic nonformulaic, whereas I would stress that expansion straddles the difference between formulaic and nonformulaic. In other words, nucleus and periphery are where "Item Plus" hits the grammatical, metrical surface. 
clei is the intonation unit, reanalyzed as a metrical unit. Two situations are possible. First, a peripheral element may fill out the metrical space unoccupied by the nuclear element, so as to complement the metrical colon. In this case the nucleus coincides with Parry's essential idea, and it is specifically the periphery (e.g., the epithets associated with a given name) to which Parry's notion of economy applies: the various epithets surrounding as peripheral expansions a given name that acts as nuclear idea tend to be unique expressions metrically. Second, the periphery may also be an entire unit with regard to another unit, an operation that mostly serves to complement the hexameter line, but that may also involve two (or more) lines. Peripheral expansion, then, may either occur unit-internally or across a unit boundary. The two kinds of expansion may occur in the same line, with the principle operating on two levels. In the example that we have seen already, for instance,

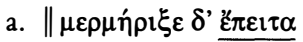
and then she pondered,
b. |
cow-eyed mistress Hera

(Il. I4.I 59)

the two ancient cult epithets for Hera, boôpis and pótnia, ${ }^{41}$ reanalyzed now as metrical elements, serve to complement the essential idea "Hera" in unit $\mathrm{b}$ both metrically and semantically. The relationships between the three elements can be seen as recursive, in that pótnia can be analyzed as a periphery to Hếrē, whereas boôpis in its turn acts as periphery to pótnia Hếrē. Represented schematically (with arrows pointing from nuclei to their peripheral extensions): ${ }^{42}$

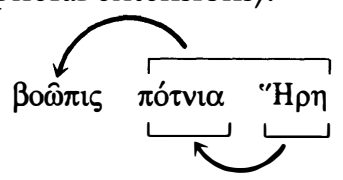

But the noun-epithet formula in its entirety can be seen as an extension to unit a. That is, it completes the metrical period, and at the same time repeats the idea "Hera" at the important moment when the plan for de-

${ }^{41}$ See Ruijgh I995: 75-77.

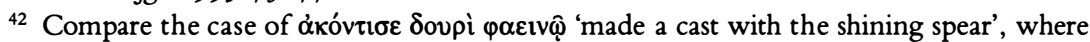

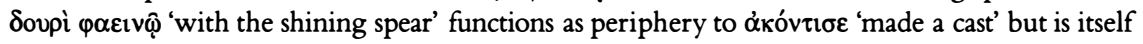
the combination of a nucleus ( $\delta$ ovpi) and a periphery ( $\varphi \alpha \varepsilon i v \hat{\varphi})$. See further Bakker and Fabbricotti I99I: 69. 
ceiving Zeus first occurs to her. ${ }^{43}$ Unit a may also be seen as peripherally extended. Its two main components are the verb and the connective particle $d(e ́)$. The latter serves as nuclear idea for the extension by épeita, as part of the peripheral system of the central particle dé, a system that also features the particle ára in the lengthened forms $d$ ' ára and d' ár' épeita. ${ }^{44}$ The nucleus-periphery relations in the passage can be represented schematically, with arrows again pointing from nuclei to their peripheries:

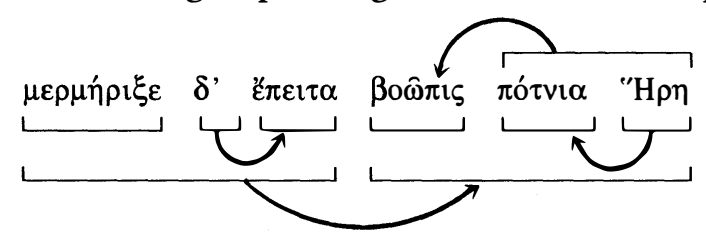

Boiled down to its "essential idea" the passage would thus be "and she pondered," but that reduction would amount to a perversion of Homeric style. It is the periphery, not the nucleus, that constitutes the essence of Homeric discourse.

Other systems of peripheral extension are the dative or prepositional expressions for "in his heart," (involving the elaborate and much discussed Homeric vocabulary for mental and emotional organs) as a peripheral element to a verb of emotion or cognition. ${ }^{45}$ Again, the peripheral extension may either fill out the metrical unit of which its nucleus is the core idea, or serve as an expanding unit itself. Of the latter possibility we have already seen an example:
a. $\| \mu \varepsilon \rho \mu \eta \dot{\rho} \rho \xi_{\varepsilon} \delta^{\prime}$ '̌ $\pi \varepsilon \imath \tau \alpha$
and then he pondered,

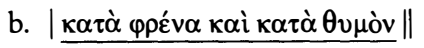
in his mind and in his spirit

(Il. 5.67 1 $;$ Od. 4.117 ; 24.235)

Unit $b$ serves as periphery to unit a and its internal structure (two functional synonyms linked by the extending particle kaí) is a characteristic example of Homeric expansion. ${ }^{46}$ The verb mermérízo 'ponder' can also be expanded within the confines of a metrical unit:

43 The noun-epithet phrase does not mark an epiphany, nor does the phrase clarify the discourse flow, since it is clear who is doing the pondering.

${ }^{44}$ See Visser 1987: 92 (and I48 for a similar treatment of $\mu \varepsilon ́ v$ ). On áp $\alpha$ see Grimm 1962;

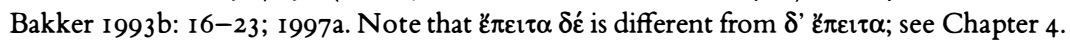

${ }^{45}$ See Jahn 1987: 247-98.

46 See also O'Nolan I978. On koi specifically, in connection with Homeric aesthetics and discourse flow, see Chapter 4 above. 


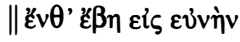

| $\pi \mathrm{o} \lambda \lambda \dot{\alpha} \underline{\varphi \rho \varepsilon \sigma \grave{i}} \mu \varepsilon \rho \mu \eta \rho i \zeta \omega v .||$ then he went to bed,

pondering many things in his mind

Other examples of peripheral expansion include the use of the particle $k a i$ as periphery to the frequent concessive participial phrases of Greek epic (kai akhnumenós per 'even though he was grieved'), ${ }^{47}$ or the systematic deployment of expressions for "with the spear" in battle narrative as peripheral element to a verb of wounding or killing. ${ }^{48}$ All these expressions are, like the epithet with regard to its name, natural extensions of the essential idea that is their nucleus.

But it should be pointed out once more that the metrical usefulness of these peripheral elements as they function in the grammar of poetry does not imply by any means that they are fillers with a meaning that is semantically empty or indifferent. The combination of particles $d$ ' ára, for example, functions as the metrical equivalent of the simple dé 'and' without loss of meaning for ára: an evidential particle that is used in conclusions drawn from visual evidence and which thus marks the narrative as deriving from a special, privileged source. ${ }^{49}$ Likewise, the original epiphanic meaning of the epithet as it is attached to the name of a hero persists in each occurrence of the new use. It is not too much to say, in fact, that this new, reanalyzed use could never have developed without the impetus of the epic epiphany.

The metrical function of epithets as peripheral elements is thus not the essence of the use and function of epithets but rather the consequence of their original, essential meaning. The connection between meter and grammar that I have stressed in this final chapter is useful in bringing out limitations of metrical utility and formulaic composition that have sometimes been neglected. Like grammar, meter is the result of saying the right thing in certain recurrent contexts. But once it has emerged as a structure in its own right, meter itself comes to constitute contexts. These metrical contexts do not call anymore for "the right thing" to be said; rather, they specify what can not be said: phrases that do not fit in the meter, and that hence do not even exist for the performers and their appreciative audiences. Speaking the special speech of the Homeric tradition requires a deeply ingrained knowl-

\footnotetext{
47 See Bakker I988: 173-86.

48 See Bakker and Fabbricotti I99I.

${ }^{49}$ See Bakker I993b; I997a.
} 
edge of the phonetic, rhythmic properties that any utterance must have in order to serve as heroic discourse. But this knowledge in itself does not tell the performer what to say: like the grammar of an ordinary language, meter in Homer is a constraint, not a compulsion. The systems of peripheral omission and extension that I briefly reviewed in this chapter are an adaptive response to the metrical constants. Resulting from those phrases that are quintessentially epic, the epithets are among the phrases that best fit the metrical contexts that they helped to create. As such they are always a good thing to say, even though sometimes it is better to say something else. 